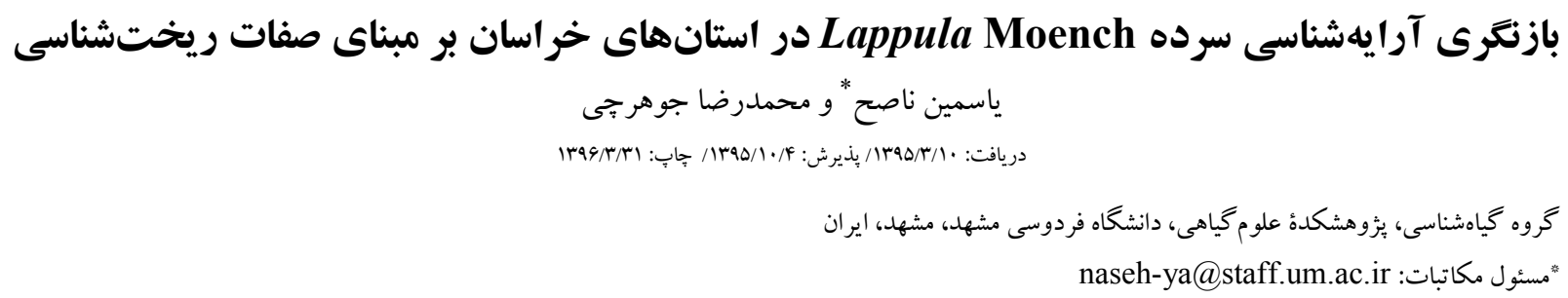

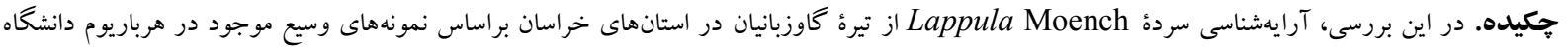

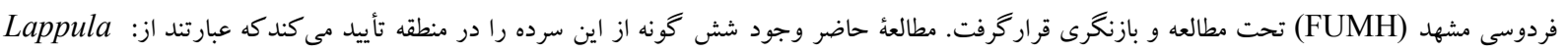

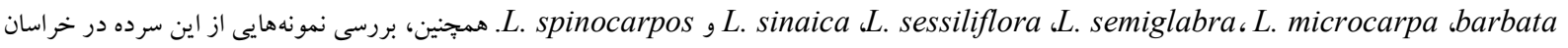

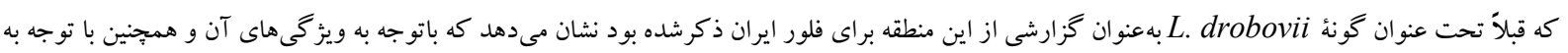

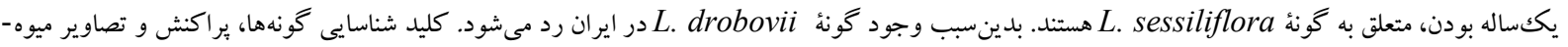
هاى آنها نيز در اين مقاله ارائه شده است.

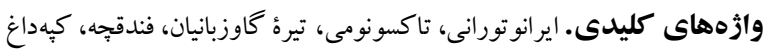

\title{
Revision of the genus Lappula Moench based on morphological characters in Khorassan Provinces (Iran)
}

Yasamin Nasseh* \& Mohammad Reza Joharchi Received 30.05.2016/ Accepted 24.12.2016/ Published 21.06.2017

Research Center for Plant Sciences, Ferdowsi University of Mashhad, Mashhad, Iran *Correspondent author: naseh-ya@staff.um.ac.ir

\begin{abstract}
A revision was carried out on the genus Lappula Moench (Boraginaceae) in Khorassan provinces. A total of herbarium specimens collected from different parts of the studied area, including the three provinces of North, Razavi and South Khorassan, were studied. All specimens are deposited in Ferdowsi University of Mashhad Herbarium, (FUMH). According to the results of the study, there are 6 Lappula species in the region: L. barbata, L. microcarpa, L. semiglabra, L. sessiliflora, L. sinaica and L. spinocarpos. In addition, by revising the annual specimens that had been previously misidentified as $L$. drobovii, a perennial species, these specimens were identified as $L$. sessiliflora. Identification key, distribution and fruit pictures in this article have been presented.
\end{abstract}

Keywords. Irano-turanian, taxonomy, Boraginaceae, Kopet-Dagh, nutlet

يراكندگى وسيعى دارند و تعدادى از آنها مناطق محدودى را

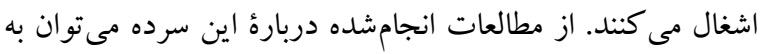

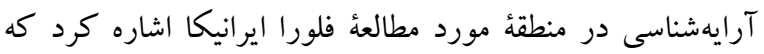

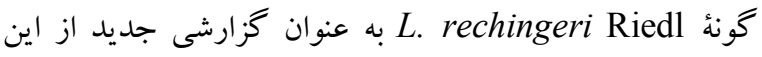
منطقه ذكر شدهاست (Riedl, 1996). همرينين، مطالعاتى درباب

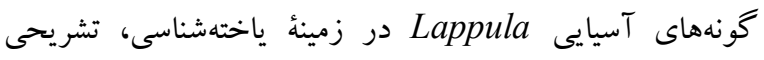
(Ovchinnikova, 2006) كردهشناسى (Hilger, 1985) ريزريختشناسى (Ovchinnikova, 2006) و ر مطالعات تبارشناسى با تأكيد بر گونهاى Lappula در آمريكاى شمالى (Rolfsmeier, 2013)

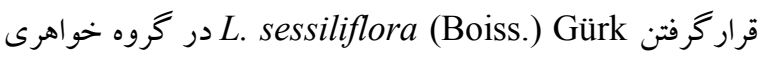
سرده .Rochelia Rchb كه داراى دو تخمك رشد يافته و ميوه
مقاله لايولا (Lappula Moench) يكى از سردههاى علفى ييجيدة تيره كاوزبانيان با قريب به ·V طونه است كه بيشتر در نواحى معتدل ارويا و آسيا، استراليا و آمريكا انتشار دارد. اين سرده شامل گروهى از گياهان تككنياى (بهاستثناى Sessiliflora Gürke) يككساله، دوساله و بهندرت جندساله است كه در سرتاسر منطقة هولاركتيك منتشر است و بيشترين تنوع آن در مناطق اير انوتورانى، سيبرى و آسياى مركزى است (Takhtajan, 1986) • انتشار گونهاى اين سرده بيشتر در نواحى استيى، بيابانى و نيمهبيابانى است (Popov, 1953; Ovechinnikova, 2006). بالغ بر .4 گونه از اين سرده براى اوراسيا شناخته شدهاست

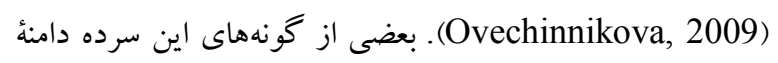


Plant Names Index

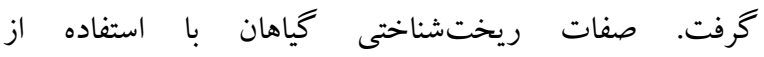

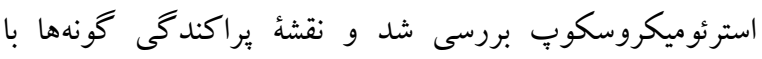

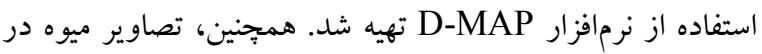
كونهاى مختلف با استفاده از دوربين ميكروسكويى ديجيتال Dino-eye AM 323B

\section{نتايج}

\section{Lappula ريختشناس}

اين سرده شامل گياهانى يككساله، دوساله و بهندرت علفىهاى

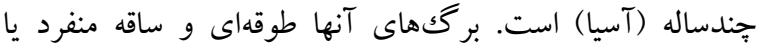
منشعب است. بركَهاى طوقهاى اغلب يُزمرده شده و در اين زمان كياه ميوه توليد مى كند. كركيوش در اين گياهان نقرهاىخاكسترى ساده و سخت است و از براكنده و تنكك تا متراكم متغير

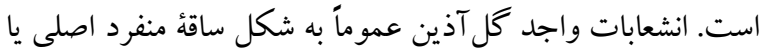

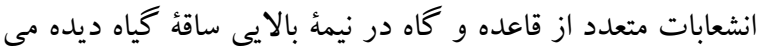
شود. كاسبر گكها آزاد از قاعده و رشديافته در زمان ميوه است.

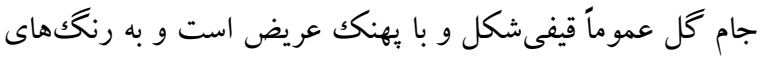
فيروزهاى، به ندرت سفيد يا كرم مشاهده مىشود. ميوه نوعى لهى

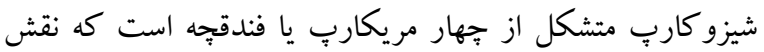

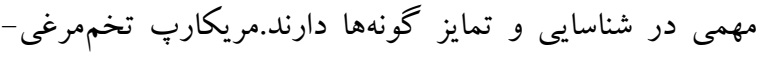

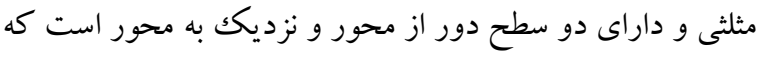

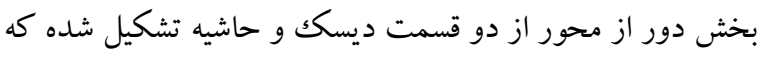

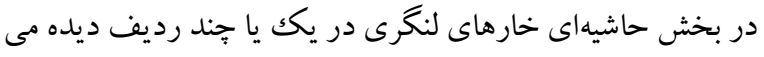

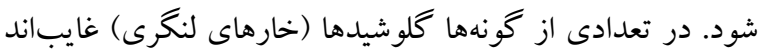
يا به زوائد كوجّك تكمهاى كاهش مى يابند و كاه در قاعده بههم -

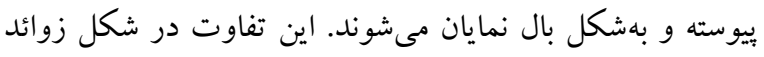

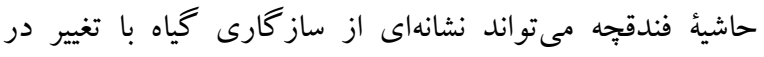

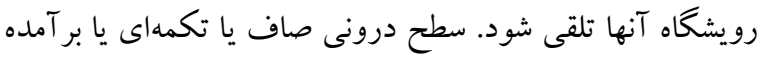

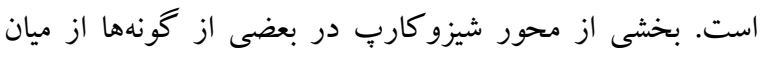

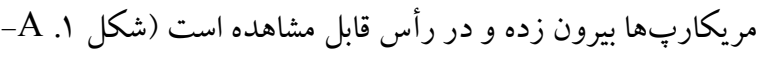

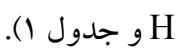

كليد شناسايى تونه ها در استانهاى خراسان

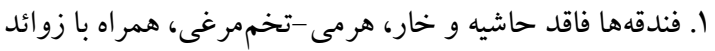

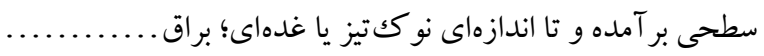

دوفندقهاى هستند بهدليل داشتن ميوهاى با جهار تخمكك رشديافته

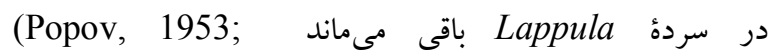
.Rolfsmeier, 2013) در ايران نيز مطالعات آرايهناختى گونههاى اين سرده با تكيه بر صفات ريختشناسى و فيلوزنى صورت گرفته است، اما هنوز

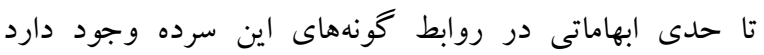
(Khatamsaz, 2002; Khoshsokhan et al., 2013) بخش نتايج و بحث بيشتر به آنها يرداخته مىشود. تفكيك و و

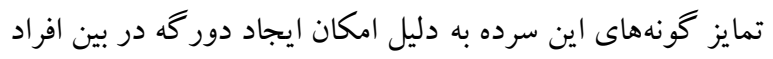

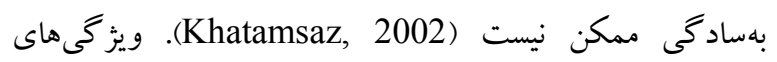
ريختى مربوط به فندقجههاى گونههاى اين سرده در تعيين حدود نهاد

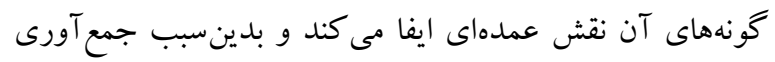

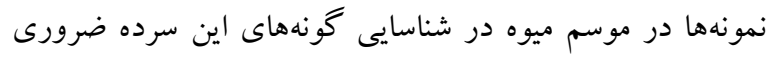

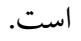

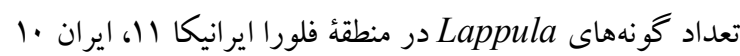

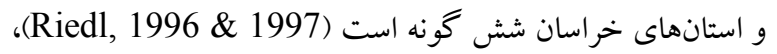

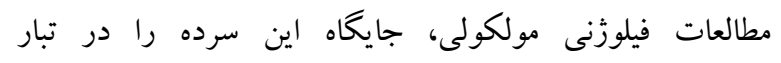
Cynoglosseae بهنك مدور و خامئ زينوبازيك منشورى تا درفشى است Langström \& Chase, 2002; Cohen \& Davis, 2012; ) .(Nazaire \& Hufford, 2012

\section{مواد و روشها}

بالغ بر ... نمونهُ هرباريومى جمع آورىشده از نقاط مختلف استانهاى خراسان شمالى، رضوى و جنوبى، كه در هرباريوم

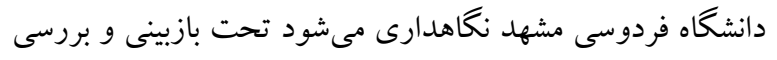

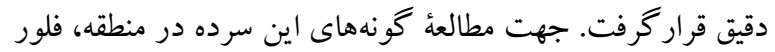
ايرانيكا (Riedl, 1996)، فلور ايران (Khatamsaz, 2002) فلور شوروى (Popov, 1953)، فلور پِاكستان ( \&azaire \&

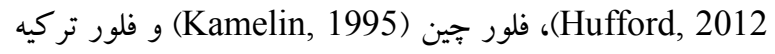
(Edmondson, 1979) Langström \& ) دستاوردهاى آنها تحت مطالعه قرار گرفتند Chase, 2002; Cohen \& Davis, 2012;; Khoshsokhan (et al., 2013; Rolfsmeier, 2013 سايتهاى The Plant list 
جوهرجیى و زنغويى YYVA

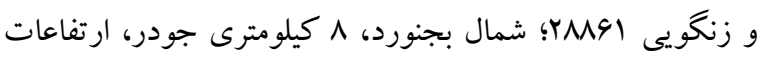

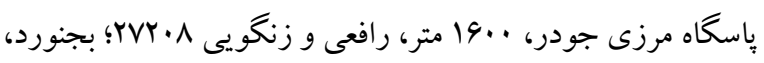

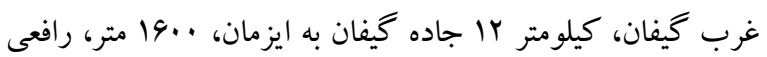
و زنغويى سYYYYY

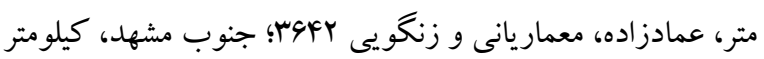

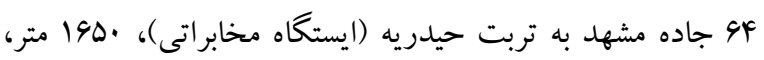
حجت و زنكويى ruv.r.

2. L. microcarpa Ledeb. \& Gürke; Engler \& Prantl., Naturl. Pflanzenfam. 4, 3a: 107 (1897).

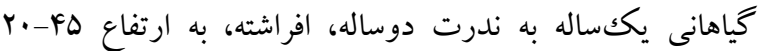

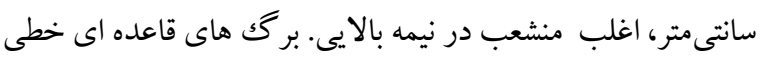

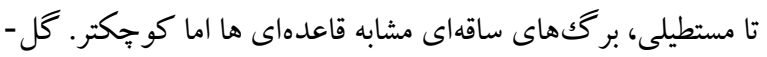

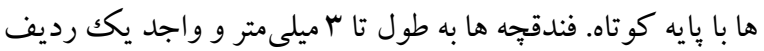
خارهاى كو تاه در حاشي؛؛ خامه بيرون زده از ميان فندجهها.

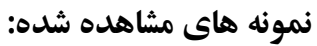
شمالغربى بجنورد، بين آيرقايه و سوخلى، جوهرجى، هاى مناهده

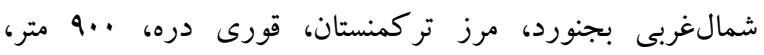

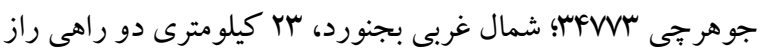

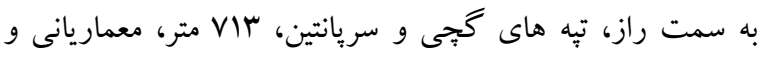

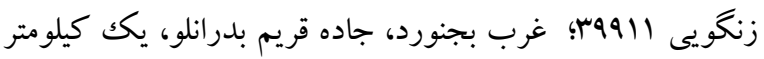

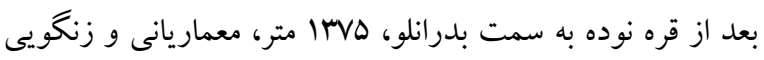

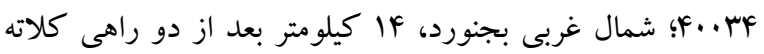

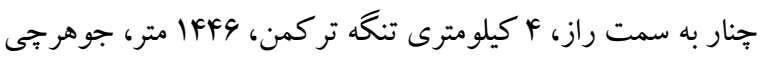

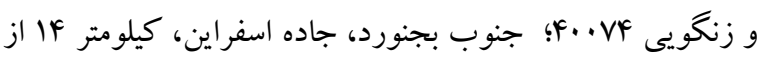

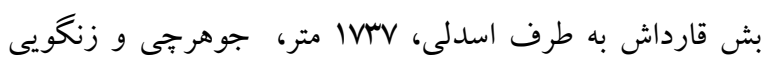

. F. 099

3. L. semiglabra Ledeb. \& Gürke; Engler \& Prantl., Naturl. Pflanzenfam. 4, 3a: 107 (1897).

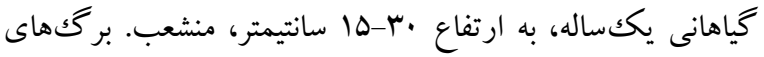

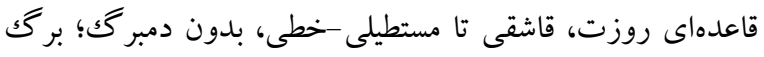
هاى ساقه اى مستطيلى باريكك تا وازنيزه ای. كل ها ها با بايه كوتاه

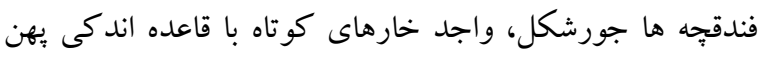

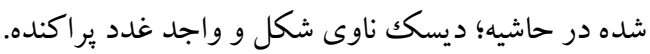

نمونه هاى مشاهده شده:

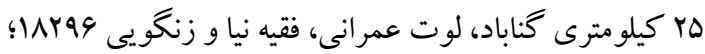

L. spinocarpos (Forssk.) Asch. ex Kuntze

r........ - فندقها واجد حاشيه و خار . r. فندقها با حاشيئ باريكك و زوائد خارمانند كوتاه و يا غدهمانند،

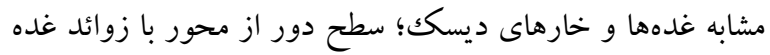

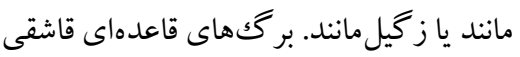
L. sinaica (A.DC.) Asch. \& Schweinf. - فندقها با حاشئ مشخص و خارهاى طويل. بر گكهاى قاعدهاى

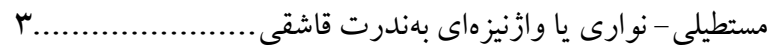

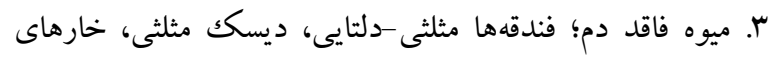

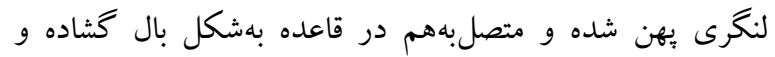

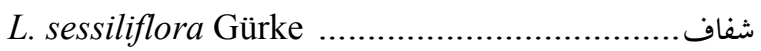
- ميؤ داراى دم مشخص؛ فندقهها واجد خارهاى لنكرى با قاعدة

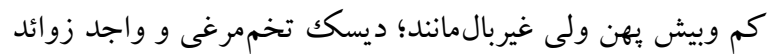
r..... تكمهاى يا خار مانند كو تاه.

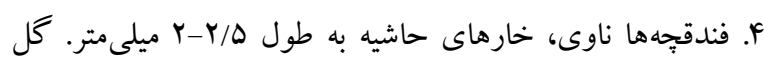

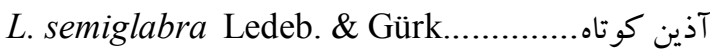
- فندقجهها تخممرغى، خارهاى حاشيه حداكثر به طول تا ب ميلى

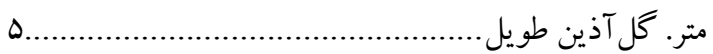

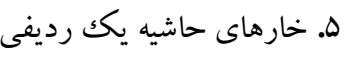
L. microcarpa Ledeb. \& Gürke.

- خارهاى حاشيه فندقجّهُ دو يا بهندرت جند رديفى.................... L. barbata (M. Bieb.) Gürke.

در زير شرح مختصرى از گونه ها با ذكر آدرس نمونه هاى مشاهده شده از گونه هاى مورد مطالعه آمده است:

1. L. barbata (M.Bieb.) Gürke; Engler \& Prantl., Naturl. Pflanzenfam. 4, 3a: 107 (1897).

گياهانى دوساله يا يككساله، افراشته به ارتفاع •ro-4 سانتىمتر،

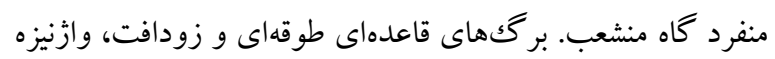

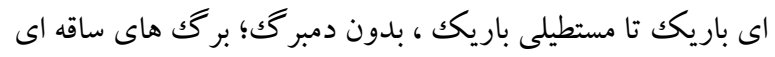

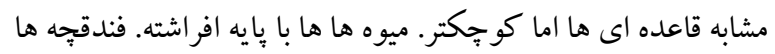
تخم مرغى، جورشكل، واجد دو رديف زوائد خارى در حاشيه،

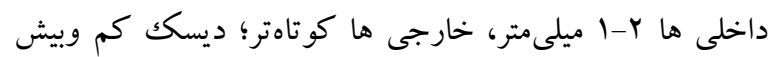
ناوى شكل و واجد غدد ير اكنده، خامه بيرون زده از ميان فندجهها. نمونه هاى مشاهده شده:

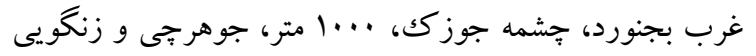
 
جدول ا- صفات مقايسهاى گونهاى سرده لإيو لا در استانهاى خراسان.

Table 1. Comparative characters of the genus Lappula in Khorassan Provinces.

\begin{tabular}{|c|c|c|c|c|c|}
\hline $\begin{array}{c}\text { صفت } \\
\text { Character } \\
\text { Sونه } \\
\text { Species }\end{array}$ & $\begin{array}{l}\text { زوره } \\
\text { Life } \\
\text { period }\end{array}$ & $\begin{array}{c}\text { زوائد سطح فندقه } \\
\text { Appendages on achene surface }\end{array}$ & $\begin{array}{l}\text { خار حاشيه فندقه } \\
\text { Marginal achene } \\
\text { glochid }\end{array}$ & 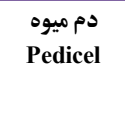 & $\begin{array}{l}\text { رديفهاى خار حاشيه فندقه } \\
\text { Marginal achene } \\
\text { glochid rows }\end{array}$ \\
\hline $\begin{array}{c}L . \\
\text { microcarpa }\end{array}$ & $\begin{array}{c}\text { يككسالد ياله } \\
\text { annual } \\
\text { or } \\
\text { biennial }\end{array}$ & $\begin{array}{l}\text { فاقد زائده يا يكك رديف طولى خار كو تاه در خط ميانى } \\
\text { without appendage or a glochidate row in the } \\
\text { middle line }\end{array}$ & $\begin{array}{l}\text { واجد خار } \\
\text { glochidate }\end{array}$ & $\begin{array}{c}\text { pedicellate } \\
\text { peda }\end{array}$ & $1(-2)$ \\
\hline L. barbata & $\begin{array}{c}\text { دككساله يا } \\
\text { دوساله } \\
\text { annual } \\
\text { or } \\
\text { biennial }\end{array}$ & $\begin{array}{l}\text { فاقد زائده يا يكت رديف طولى خار كو تاه در خط ميانى } \\
\text { without appendage or a glochidate row in the } \\
\text { middle line }\end{array}$ & واجد خار glochidate & $\begin{array}{c}\text { دمدار } \\
\text { pedicellate }\end{array}$ & 2 \\
\hline L. sinaica & 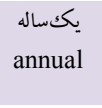 & $\begin{array}{c}\text { فاقد زائده } \\
\text { without appendage }\end{array}$ & $\begin{array}{l}\text { واجد زوائد غده ماند } \\
\text { with gland like } \\
\text { appendages }\end{array}$ & 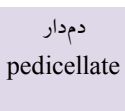 & - \\
\hline L. semiglabra & 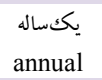 & $\begin{array}{c}\text { فاقد زائده } \\
\text { without appendage }\end{array}$ & واجد خار & 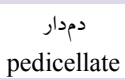 & 1 \\
\hline L. sessiliflora & $\begin{array}{l}\text { ئكual } \\
\text { annul }\end{array}$ & فاقد زائده & $\begin{array}{l}\text { واجد خار glochidate } \\
\text { glo }\end{array}$ & $\begin{array}{l}\text { فاقد دم non } \\
\text { pedicellate }\end{array}$ & 1 \\
\hline $\begin{array}{c}L . \\
\text { spinocarpos }\end{array}$ & $\begin{array}{l}\text { يك } \\
\text { annual }\end{array}$ & $\begin{array}{c}\text { زوائد تكمهاى هماندازه } \\
\text { tuberculated appendages with equal size }\end{array}$ & $\begin{array}{c}\text { فاقد خار } \\
\text { non glochidate }\end{array}$ & 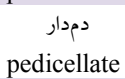 & - \\
\hline $\begin{array}{l}\text { L. } \\
\text { spinocarpos } \\
\text { subsp. } \\
\text { ceratophora }\end{array}$ & $\begin{array}{l}\text { - } \\
\text { annual }\end{array}$ & $\begin{array}{c}\text { tuberculated appendages with different size } \\
\text { tوائد تكماى در اندازهاى متفاوت }\end{array}$ & 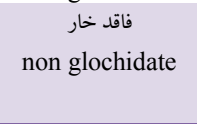 & $\begin{array}{l}\text { pedicellate } \\
\text { pedis }\end{array}$ & - \\
\hline
\end{tabular}

در زمان ميوه ^-Y ميلى متر و خميده. فندقجهها Y ميلى متر، تخم مرغى، غده دار؛ حاشيه نامشخص و كاهى با تعداد كمى زوائد خار مانند كو جָك؛ خامه بيرون زده از ميان فندجه ها. نمونه هاى مشاهده شده:

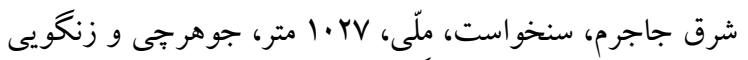

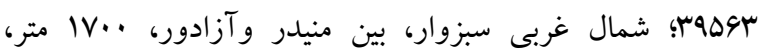
 بجنورد، بين كال ايمانى وتنگه تر كمن، شمال كال ايمانى، . 9.9

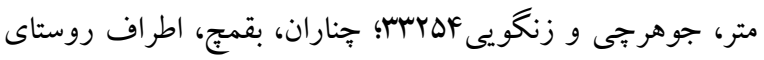

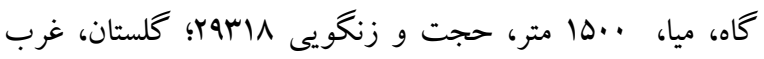

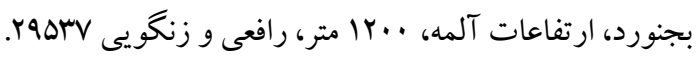

4. L. sinaica (A.DC.) Asch. \& Schweinf; Mem. Inst. Egypt. 2: 111(1887).

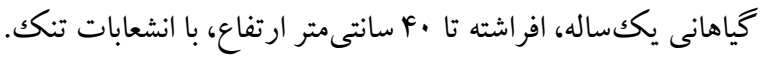
برگك هاى قاعده اى قاشقى تا وازٔنيزه اى، دمبرگك دار؛ برگك هاى ساقه اى بدون دمبر گَ. دمگل ها كو تاه، در زمان ميوه ^-ب ميلى متر

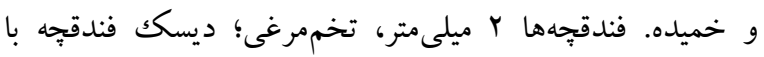
برجستگى هاى تكمهاى بر اكنده و حاشيه نامشخص و كاهى با -
شرق بيرجند، بين طبس مسينا و كزيك،، ·ذها متر، جوهرجى و

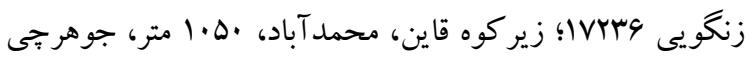

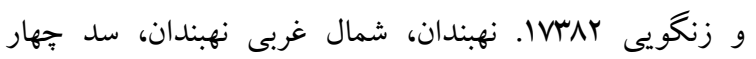

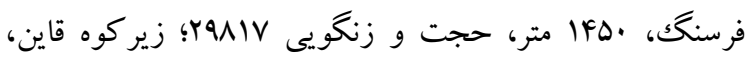
شاهرخت به آهنخر ان، كيلومتر 19، •ه1 متر، رافعى و حسين زاده

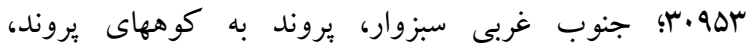

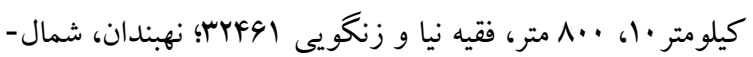
غربى نهبندان، كيلومتر ها نهبندان به جهار فرسخ، . . F متر، فقيه نيا و زنكويى

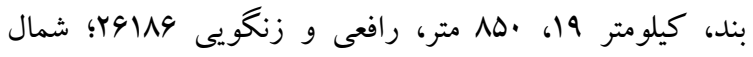

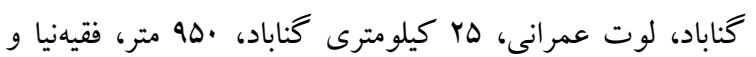

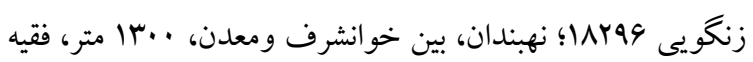

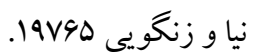

L. sessiliflora Gürke; Engler \& Prantl., Naturl. Pflanzenfam. 4, 3a: 107 (1897).

كياهانى يككساله، افراشته، به ارتفاع تا هاسانتىمتر، با انشعابات

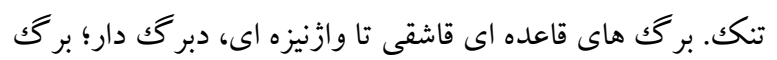
هاى ساقهاى بدون دمبر گك. گل ها با يايه كوتاه. دمخل ها كوتاه، 

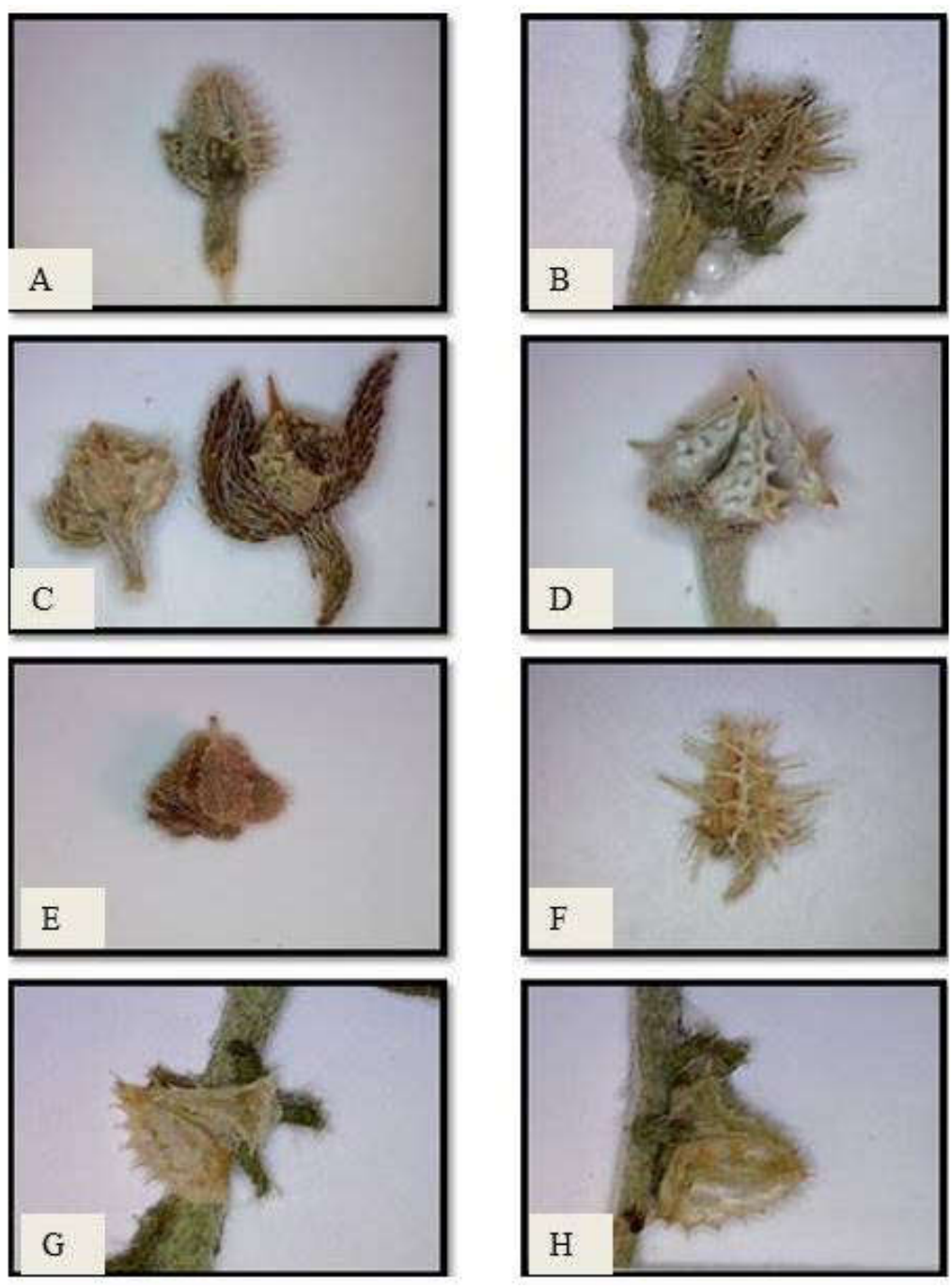

شكل ا-ميؤ شيزو كارب گونهاى سرده لإيولا در استانهاى خراسان.

Fig. 1. Schizocarps in Lappula species in Khorassan Provinces.

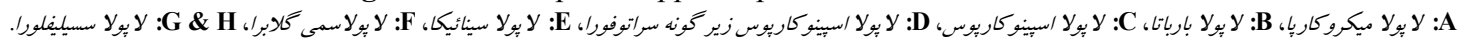
A: L. microcarpa, B: L. barbata, C: L. spinocarpus, D: L. spinocarpus subsp. ceratophora, E: L. sinaica, F: L. semiglabra, G \& H: L. sessiliflora.

19. متر، فقيهنيا و زنكويى 19هD؛ شمال غربى بجنورد، بين دو راهى جر كلان- غلامان و باغلق، قرق باغلق، مقابل جهارواى لهاى

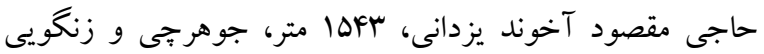

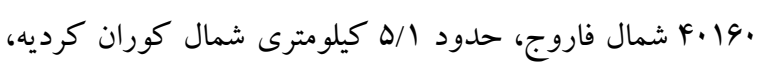

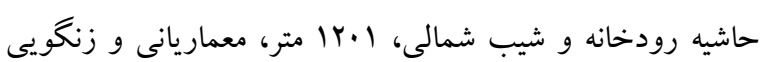
FrVGF

5. L. spinocarpus (Forssk.) Asch. ex Kuntze; Acta Hort. Petrop. 10: 215 (1887).

كياهانى يككساله، ، افراشته تا خوابيده، منشعب. بركى هاى قاعده

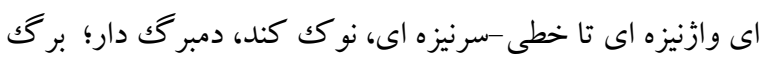

تعداد كمى زوائدخارمانند كوجِك.

نمونه هاى مشاهده شده:

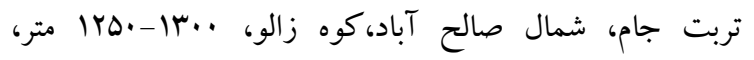
جوهرجى و زنغويى هابه

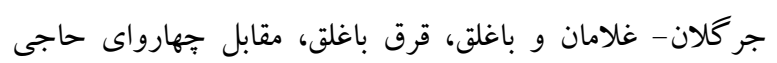

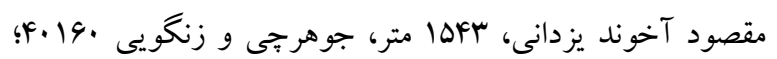

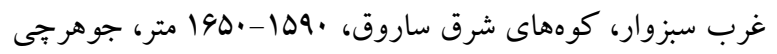

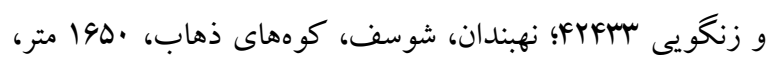

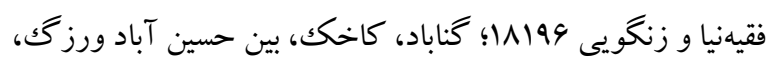


كياهى دوساله است و ميوه آن داراى ا تا Y فندقه بالدار فنجانى شكل بعلاوه 1 تا Y فندقه بدون بال است، درحالى كه sessiliflora و فنجانى شكل است و سه فندقه ديخر بدون بال هستند. بنابر اين با توجه به نمونهاى جمع آورى شده موجود در اين هرباريوم،

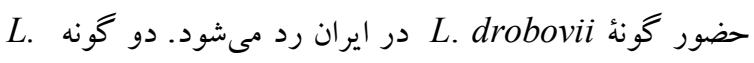
Www. the plant list در وبگ L. patula و semiglabra مترادف با گونه L. marginata قرارگرفتهاند، ولى بر اساس مطالعات مولكولى اخير، اين دو آرايه به عنوان دو كونهُ معتبر

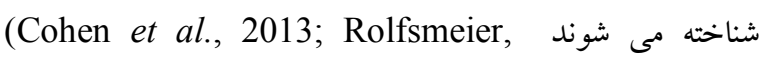
(2013. در فلور ايران، اين دو گونه از شمالشرقى ايران و استان هاى خراسان هم گز ارش شدهاند. از بررسى صفات ريختش شناسى اين دو گونه بهويزه تفاوت در فندقجههاى آنها، به نظر مىرسد كه كليه نمونهاى جمع آورىشده از منطقه تحت مطالعه با فندقجه. هاى ناوىشكل و تعداد خارهاى بلندتر و بيشتر، به كونهُ semiglabra سرنيزهاى و خارهاى كوتاهتر و با تعداد كمتر در ميان گياهان جمع آورىشده از اين منطقه مشاهده نشد. همجينين، با توجه به مطالعات مولكولى انجامشده بر روى كونههاى Lappula

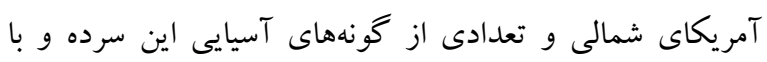
توجه به نتايج حاصل، مطالعات گستردهترى در زمينه

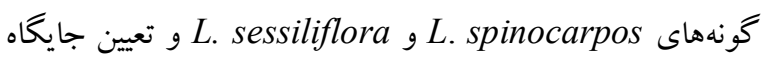
واقعى آنها ضرورى است، زيرا با توجه به اين مطالعات و

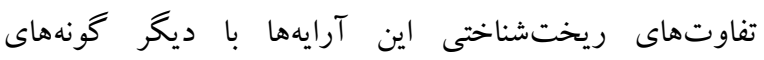
Lappula سردهاى خويشاوند ديخر تعلق داشته باشند. صرفنظر از اين

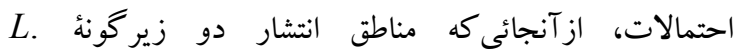
L. spinocarpus, spinocarpus subsp. ceratophora subsp. spinocarpus

$$
\text { مى تو انند واريتهايى از اين گو نه محسوب شوند. }
$$

با مطالعه صفات ريخت شناسى آرايههاى L. microcarpa و

مشخص مى Kردد كه اين دو خويشاوندان بسيار L. barbata

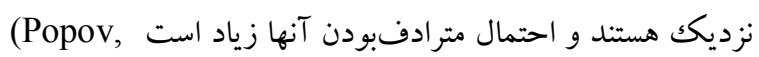
1953; Akhani, 1998) لذا مطالعات مولكولى براى بررسى اين كونهها جهت تأييد يا رد اين عقيده ضرورى است. البته طبق -
هاى ساقه اى مشابه قاعدهاىها و كو جֶكتر. دمگل كوتاه، در هنگام ميوه تا ه ميلى متر طول. فندقجه ها منشورى، در قاعده وسيع شده، در سطح واجد زوائد تكمه اي بالدار و واجد زوائد دندانه ای در حاشيه.

نمونه هاى مشاهده شده:

\section{L. spinocarpus subsp. spinocarpus}

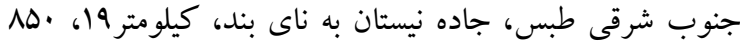

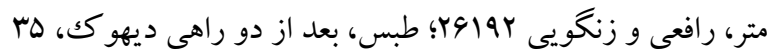

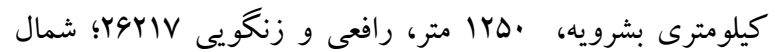

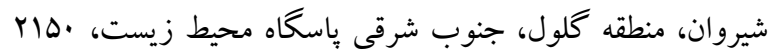

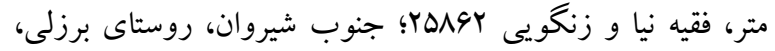

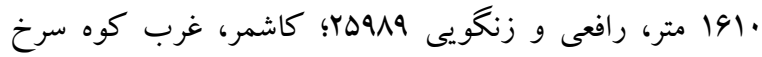

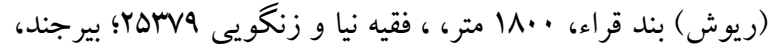
خوسف به معدن قلعه زرى، كيلومتر ·ا، .10 متر، فقيه نيا و

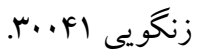

L. spinocarpus subsp. ceratophora (M.Pop.) M. Pop.; Fl. USSR. 19: 417 (1953). تربت جام، مشهد به صالح آباد، بين بغبغو و نعتو، •ها متر،

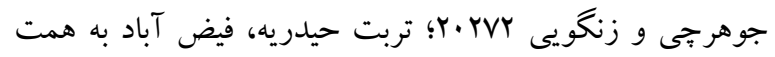

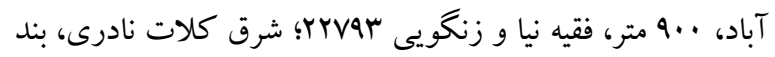

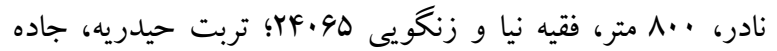

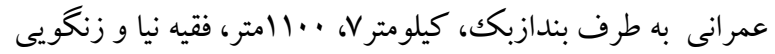

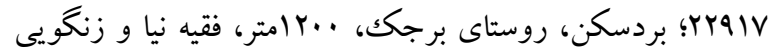

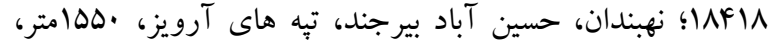

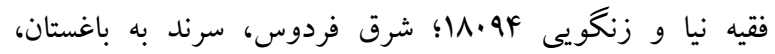

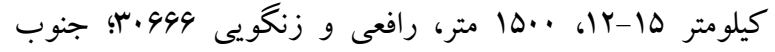
شرقى طبس، جاده معدن زغال سنگ ير اوده به طبس، كيلومتر

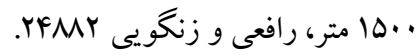

كونهُ L. drobovii بهنوان گزارشى جديد از شمال شرق كشور، استان خراسان رضوى، براى فلور ايران ذكر شده بود ب. (Khatamsaz \& Joharchi, 1996; Khatamsaz, 2002) بررسى مجدد نمونه هاى شناسائى شده موجود در هرباريوم دانشگاه فردوسى مشهد كه باعنوان L. drobovii شناسائى شده بودند، مشخص شد تماماً Lessiliflora 


\section{REFERENCES}

Akhani, H. 1998. Plant biodiversity of Golestan national park, Iran. - Biologiezentrum des O.Ö. Landesmuseums $411 \mathrm{pp}$.

Cohen, J.I. and Davis, J.I. 2012. Molecular phylogenetics, molecular evolution and patterns of clade support in Lithospermum (Boraginaceae) and related taxa. - Syst. Botany. 37: 490-506.

Cohen, J.I., Zhang, M.L. and Jian-Feng. H. 2013. Phylogenetic analysis of Lappula Moench. (Boraginaceae) based on molecular and morphological data. - Plant Syst. Evol. 299: 913-926.

Edmondson, J.R. 1979. Lappula Moench. - In: Davis, P.H. (ed.), Flora of Turkey and the East Aegean Islands 6: 2551-2261. - Edinburgh University Press, Edinburgh.

Hilger, H. 1985. Ontogenie, morphologie und systematic Bedeutungge flüelter und glochidientragender Cynoglosseae und Eritrichieaefrüchte (Boraginaceae). - Botanische Jahrbücherfür Systematic, Pflazengeschichite und pflanzengeographie. 105: 323-378.

Kamelin R.V. 1995. Boraginaceae. - In: Wu, Z.Y., Raven, P.H. (eds), Flora of China, - Science Press, Beijing, 16: 329-427.

Khatamsaz, M. and Joharchi, M. 1996. Some new records of Boraginaceae from Iran. - Iranian J. Bot. 7: 11-14.

Khatamsaz, M. 2001. Pollen morphology of Iranian Boraginaceae family and its taxonomic significance. - Iranian J. Bot. 9: 27-40.

Khatamsaz, M. 2002. Boraginaceaein. - In: Assadi et al. (eds), Flora of Iran 39. - RIFR, Tehran, 505 pp.

Khoshsokhan, M., Kazempour Osaloo, S., Saadatmand, S. and Attar, F. 2010. Molecular phylogeny of Rochelia (Boraginaceae) basedon nrDNA ITS and cpDNAtrnL-F sequences. - Iranian J. Bot. 16: 22-29.

Lagstrom, E. and Chase, M.W. 2002. Tribes of Boraginaceae (Boraginaceae) and placement of Aniphytum, Echichlion, Ogastemma and Serigostoma: A phylogenetic analysis based on atp B plastid DNA sequence data. - Plant Syst. Evol. 234: 137-143.

Nazaire, M. and Hufford, L. 2012. A broad phylogenetic analysis of Boraginaceae: implications for the relationnships of Mertensia. - Syst. Botany 37: 758-783.

Ovchinnikova, S. 2006. Ultrasculptural features of fruit surface in subtribe Echinosperminae (tribe Eritrichieae, Boraginaceae) (in Russian with English abstract). - Bot. Zhurn. 91:105-116.

Ovchinnikova, S. 2009. On the position of the tribe Eritrichieae in the Boraginaceae systematic. - Bot. Serb. 33: 141-146.

Popov, M.G. 1953. Boraginaceae. - In: Schischkin, B.K. (ed.), Flora USSR 19: 97-691. - Izdatel'stvo Akademii Nauk SSSR, Moskwa, Leningrad.

Riedl, H. 1996. Studies in the genus Lappula (Boraginaceae) I. Lappula in the "Flora Iranica" region. - Ann. Naturhist. Mus. Wien. 98: 79-86.

Riedl, H. 1967. Boraginaceae. - In: Rechinger, K.H., (ed.), Flora Iranica, Lfg. 48. Akademische Druck-und Verlagsgesellschaft, Graz, Austria, 281 pp.

Rolfsmeier, S.J. 2013. Taxonomy and phylogeny of the genus Lappula Moench (Boraginaceae) in North
نظر Buzentsov و Boissier، يوشش فندقجه در Larbata، همانند Microcarpa

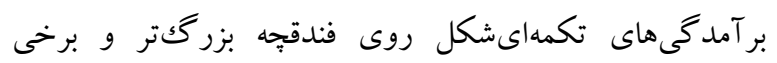

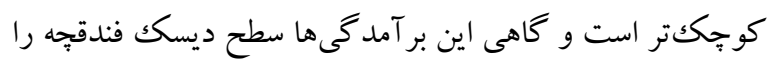
در امتداد خط طولى ميانى بهطور كامل مىبوشاند يا در مواردى إنى

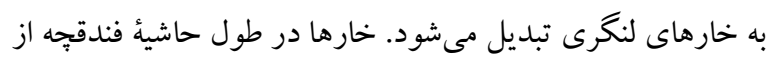

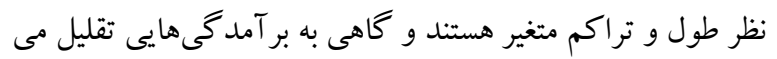

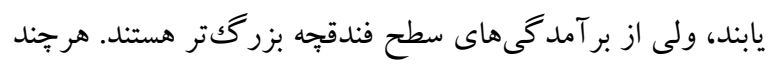
رديف ثانويهاى از خارها وجود دارد، هميشه به وضوح قابل

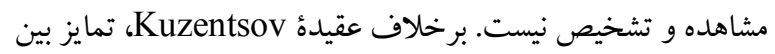

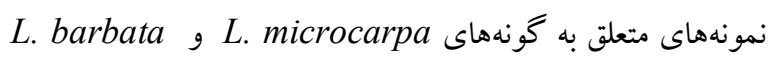

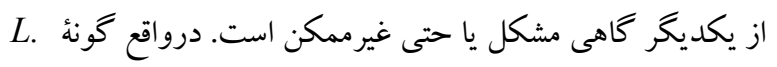

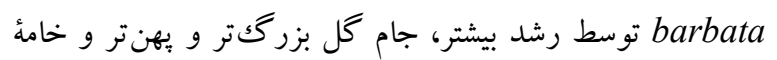

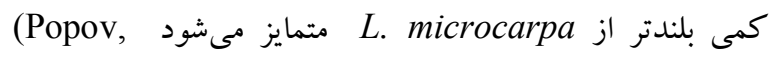
$.1953)$ درحقيقت، گونهُ موجود در كِهداغ واقع درشمال شرق ايران و

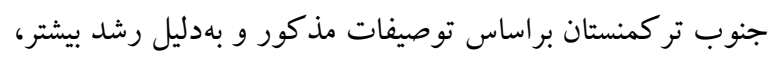

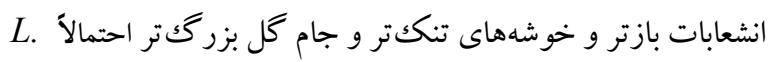
barbata

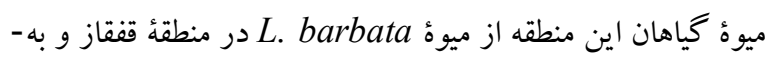

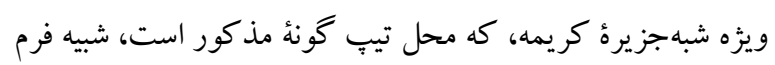

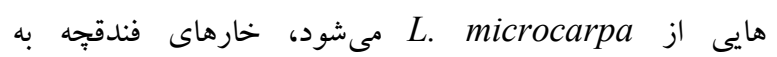
برآمدكىهاى تكمهاى كاهش مىيابند درحالى كه در جمعيت

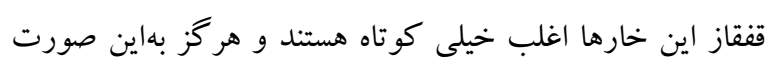
ديده نشدهاند (Popov, 1953).

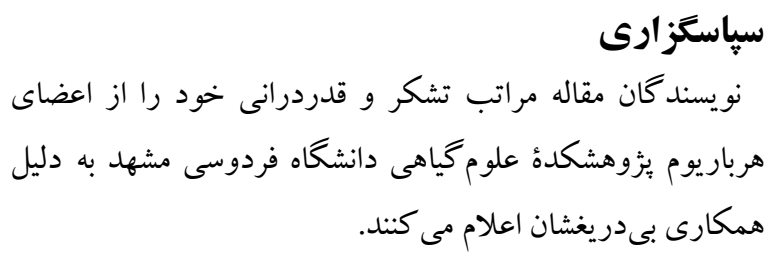


America. - Ph.D. Dissertation, Kansas State University, Manhattan, KS. 14-Zhu GL, 1-201.

Takhtajan, A. 1986. Floristic regions of the world. (T.J. Cronquist, Trans) Berkeley. - California, United States of America: University of California, $522 \mathrm{p}$.

The International Plant Names Index. 2016. Published on the internet http:www.ipni.org (accessed $1^{\text {st }}$ January 2016).

The Plant List. 2016. Version 1.1. Published on the http://www.theplant list.org (accessed $1^{\text {st }}$. January 2016).

$* * * * *$

\section{How to cite this article:}

Nasseh, Y. and Joharchi, M.R. 2017. A revision on the genus Lappul Moench based on morphological characters in Khorassan Provinces. - Nova Biol. Rep. 4: 6572.

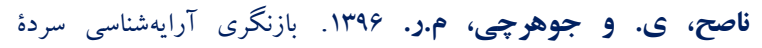

- در استانهاى خراسان بر مبناى صفات ريخت Lappula Moench

شناسى.- يافتهاى نوين در علوم زيستى F: YY-VD. 